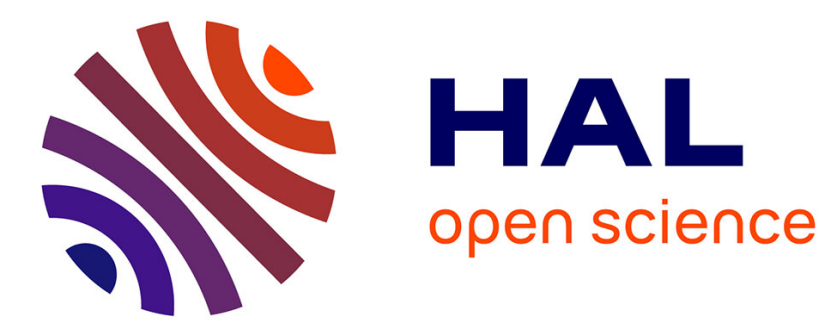

\title{
Strategic interactions and belief formation: An experiment
}

Kyle Hyndman, Antoine Terracol, Jonathan Vaksmann

\section{To cite this version:}

Kyle Hyndman, Antoine Terracol, Jonathan Vaksmann. Strategic interactions and belief formation: An experiment. Applied Economics Letters, 2010, 17 (17), pp.1681-1685. 10.1080/13504850903120691 . hal-00607238

\section{HAL Id: hal-00607238 \\ https://hal.science/hal-00607238}

Submitted on 13 Jul 2011

HAL is a multi-disciplinary open access archive for the deposit and dissemination of scientific research documents, whether they are published or not. The documents may come from teaching and research institutions in France or abroad, or from public or private research centers.
L'archive ouverte pluridisciplinaire HAL, est destinée au dépôt et à la diffusion de documents scientifiques de niveau recherche, publiés ou non, émanant des établissements d'enseignement et de recherche français ou étrangers, des laboratoires publics ou privés. 


\title{
Strategic interactions and belief formation: An experiment
}

\author{
Kyle Hyndman* \\ Antoine Terracol ${ }^{\dagger}$ \\ Jonathan Vaksmann
}

March 4, 2009

\begin{abstract}
Traditional models of belief formation in repeated games assume adaptive players who do not take strategic interactions into account. We find that these approaches are limited in the sense that people think more strategically and realize that, in contrast with the classical view, their own actions are likely to influence their opponents' behaviour.
\end{abstract}

JEL codes: C91, D83

Keywords: Game theory, Learning, Beliefs, Experiment

\section{Introduction and motivations}

In recent years, economists have studied ways to describe how people learn in a repeated game. To tackle the strategic complexity inherent in repeated games, belief learning models assume that players see their opponents' behaviour as generated by an exogenous process. Hence, typical proxies for beliefs are formed on the basis of the historical data of their opponents' play only and, according to this view, players do not realize that their own actions could influence their opponents' behaviour (i.e., strategic interactions are neglected).

In this study, we run an experiment where subjects play repeated games under various conditions which are likely to have an impact on strategic considerations that drive

*Department of Economics, Southern Methodist University, 3300 Dyer Street, 301R, Dallas, TX 75275, hyndman@smu.edu

${ }^{\dagger}$ EQUIPPE, Universités de Lille, and Centre d'Économie de la Sorbonne, Université Paris 1 - Panthéon Sorbonne, CNRS, terracol@univ-paris1.fr

${ }^{\ddagger}$ Centre d’Économie de la Sorbonne, Université Paris 1 - Panthéon Sorbonne, CNRS, jonathan.vaksmann@univ-paris1.fr 
players' behaviour. We find that when players have relatively high incentives to behave strategically, their reasoning is more thoughtful than widely assumed.

\section{Experimental design and procedures}

In order to examine the role of strategic interactions in repeated games, we conducted four experiments. Inexperienced subjects were brought into the experimental laboratory at the University of Paris 1 Panthéon-Sorbonne ${ }^{1}$ and were asked to play one of the games in Table 1 in fixed pairs for a total of 20 periods. Subjects were randomly assigned the role of either a row $(r)$ or a column (c) player and were told that they would remain in that role for the duration of the experiment. Payoffs were denominated in experimental currency units and were converted into Euros at the conclusion of the experiment. Subjects earned, on average, $€ 14.1$ for their participation. In addition to written instructions (available upon request), subjects received an oral summary of the instructions.

All of our games have two pure-strategy Nash equilibria and one mixed-strategy Nash equilibrium. In these games, the pure strategy equilibria are Pareto rankable, both players strictly prefer the equilibrium $(X, X)$ to the equilibrium $(Y, Y)$. The mixed strategy equilibrium was $\{(0.8,0.2) ;(0.8,0.2)\}$.

One of the main reasons for neglecting strategic interactions in repeated games is that such behaviour is cognitively demanding. We conjecture that, when given sufficiently strong incentives, players are more likely to take strategic interactions into account. We designed our games to vary players' tendency to think more strategically. In order to measure this, we vary parameters which are likely to play an important role. First, we vary the cost of mis-estimating the opponent's behaviour. Second, we vary the gains from convergence to the Pareto equilibrium, which is likely to alter players' incentives to use strategic interactions in order to coordinate efficiently.

Denote $\pi_{i}\left(a, a^{\prime}\right), i \in\{r, c\}$, player $i$ 's payoff when he plays $a$ and his opponent plays $a^{\prime}$ and $E\left[B R_{i}(p)\right]\left(E\left[\overline{B R}_{i}(p)\right]\right)$ player $i$ 's expected payoff when he best-responds (does not best-respond) given $p$, the probability attached to $X$. Let also $p^{*}$ be the equilibrium mixing probability. The expected payoff loss of mis-estimating the opponent's behaviour is:

$$
E\left[B R_{i}(p)\right]-E\left[\overline{B R}_{i}(p)\right]=\theta_{i} \cdot\left|p-p^{*}\right|
$$

with

$$
\theta_{i}=\pi_{i}(X, X)-\pi_{i}(Y, X)+\pi_{i}(Y, Y)-\pi_{i}(X, Y) .
$$

Therefore, $\theta_{i}$ is our cost parameter, it is actually the optimization premium parameter of Battalio, Samuelson, and Van Huyck (2001). We conjecture that players will be more inclined to form their beliefs carefully when this cost is high.

\footnotetext{
${ }^{1}$ The experiment was programmed using 'Regate' (Zeiliger, 2000).
} 
Similarly, if the reward from coordinating on the Pareto efficient equilibrium is high, we would expect players to play strategically in order to "teach" their opponent (Camerer, Ho, and Chong, 2002, Ehrblatt, Hyndman, Ozbay, and Schotter, 2009, Terracol and Vaksmann, 2009) and thus to pay greater attention to strategic interactions. Therefore, in our experiments, we also vary the gain from moving from the inefficient to the efficient equilibrium. More precisely, for player $i, i \in\{r, c\}$, the gain parameter can be written as:

$$
\psi_{i}=\frac{\pi_{i}(X, X)-\pi_{i}(Y, Y)}{\pi_{i}(Y, Y)} .
$$

We have four games according to the size (High or Low) of the cost and gain parameters. In Table 1, the first letter above each game refers to the size of the gain parameter while the second stands for the size of the cost parameter. Notice that in all of our games the column player's payoffs are identical, while the row player's payoffs vary according to the cost and gain parameters. This gives us interesting testable implications across players. $^{2}$

In this study we must elicit players' beliefs in order to perform a detailed examination of strategic thinking. In each round, before choosing their action, subjects reported their beliefs about the likely action of their match in that round. That is, they reported a probability vector, $b=\left(b_{X}, b_{Y}\right)$, where $b_{a}$ represents the belief held by the subject associated to the action $a$ of his opponent $(a \in\{X, Y\}$ ). A player's payoff when he reports $b$ and his opponent actually uses action $a$ is given by the following quadratic scoring rule: ${ }^{3}$

$$
\left[8-4\left(\left(1-b_{a}\right)^{2}+b_{a^{\prime}}^{2}\right)\right], a \neq a^{\prime} .
$$

At the end of each round, subjects were informed about the actions and stage game payoffs of both players.

\section{Results}

The aim of our study is to test whether players think strategically and anticipate their opponents' reactions to their own actions. Because beliefs may also depend on the history of the opponents' past actions, as postulated by traditional proxies used to describe players' belief-formation process, one must filter out the impact of these past actions to avoid spurious correlations between $a_{i}(t-1)$, player $i$ 's own action in the previous round, and his current beliefs. We thus examine the differences between elicited beliefs and beliefs based on the past history of the game.

\footnotetext{
${ }^{2}$ In games $H L, H H, L L$ and $L H$ we have respectively $34,32,38$ and 30 subjects. $\psi_{r}$ is 2.33 in games $H L$ and $H H$ and 0.67 in games $L L$ and $L H . \theta_{r}$ is 5 in games $H L$ and $L L$ and 15 in games $H H$ and $L H . \psi_{c}$ and $\theta_{c}$ are respectively 0.41 and 40 in all games.

${ }^{3}$ See Nyarko and Schotter (2002) for a detailed description of this procedure.
} 
Adopt the terminology of Nyarko and Schotter (2002) and refer to beliefs based only on the history of the opponents' actions as "empirical" beliefs. Denote empirical beliefs by $\tilde{B}_{i}^{a}(t)$ and elicited beliefs by $B_{i}^{a}(t)$. Next define $D_{i}^{a}(t)=B_{i}^{a}(t)-\tilde{B}_{i}^{a}(t)$ to be the difference between elicited and empirical beliefs. Observe that since $\tilde{B}_{i}^{a}(t)$ is conditional on the history of the opponents' past actions, but not on the action chosen by player $i$ in period $t-1$ (i.e., $a_{i}(t-1)$ ), then if $D_{i}^{a}(t)$ depends on $a_{i}(t-1)$, so too must elicited beliefs. In this case, we may conclude that players realize the influence of their own actions on their opponents' behaviour. In other words, players would take strategic interactions into account. We chose to model empirical beliefs with the $\gamma$-weighted beliefs model of Cheung and Friedman (1997), where the belief held by player $i$ about the probability that player $j$ will play action $a$ in round $t+1$ is given by:

$$
\tilde{B}_{i}^{a}(t+1)=\frac{I_{\left(a_{j}(t)=a\right)}+\sum_{u=1}^{t-1} \gamma^{u} I_{\left(a_{j}(t-u)=a\right)}}{1+\sum_{u=1}^{t-1} \gamma^{u}}
$$

where $I_{\left(a_{j}(t)=a\right)}$ equals one if player $j$ has played action $a$ in round $t$, and zero otherwise. Actions played in a given round are discounted with time at rate $\gamma \in[0,1]$. According to these empirical proxies for beliefs, players form conjectures only on the basis of the history of their opponent's actions; hence, strategic considerations do not matter.

We estimate the model of equation (1) at the individual level, and compute $\hat{D}_{i}^{a}(t)$, as the difference between elicited beliefs and estimated empirical beliefs in round $t$.

We then examine whether $\hat{D}_{i}^{a}(t)$ can be explained by the action taken by player $i$ in the previous round $-a_{i}(t-1)$. If so, this would indicate that players (at least partly) base their actions on motivations beyond those suggested by classical adaptive proxies. For this reason, we refer to it as a sophistication bias.

We first display a graphical analysis that can be complemented with paired t-tests. Figure 1 shows, for each game and each type, the mean value of $\hat{D}_{i}^{X}(t)$ according to whether or not $X$ was played in the previous round. ${ }^{4}$

It is clear from Figure 1 that the $\hat{D}_{i}^{X}(t)$ are almost always higher when $X$ rather than $Y$ has been played in the previous round. Moreover, the residuals tend to be positive when $a_{i}(t-1)=X$ and negative when $a_{i}(t-1)=Y$. This is consistent with the hypothesis that players take their own actions into account when forming beliefs.

We also run a series of paired t-tests on the difference of the mean $\hat{D}_{i}^{X}(t)$ at the individual level. In other words, we test whether, when one controls for the past history of the opponent's actions, beliefs towards $X$ vary significantly according to the player's previous action. The results are displayed in Table 2. The first line shows the mean differences between $\hat{D}_{i}^{X}\left(t \mid a_{i}(t-1)=X\right)$ and $\hat{D}_{i}^{X}\left(t \mid a_{i}(t-1)=Y\right)$. The following two lines give the $\mathrm{p}$-value and the number of observations, respectively. ${ }^{5}$

\footnotetext{
${ }^{4}$ Note that $\hat{D}_{i}^{Y}(t)=-\hat{D}_{i}^{X}(t)$, so our conclusions are valid across actions.

${ }^{5}$ The number of observations varies within games since some players never played $X$ or never played $Y$. These players are thus excluded from this analysis.
} 
These results are broadly consistent with our conjectures and show that row players' beliefs vary significantly according to his previous action in all games except game $L H$ where their incentives to pay attention to strategic interactions are relatively weak. For column players, whose incentives remain unchanged through games, the differences are generally insignificant with the exception of the difference in game $H L$.

Does the sophistication bias vary according to the cost and gain parameters? If so, are one's own gains and costs the only parameters that matter, or do the gains and costs of the opponent also influence the way players form their beliefs?

To answer this question, we estimate fixed-effect regressions of the residuals on the previous action, and the previous action interacted with the gain and cost parameters of both players:

$$
D_{i}^{X}(t)=\beta_{0}+\left[\beta_{1}+\beta_{2} \psi_{i}+\beta_{3} \theta_{i}+\beta_{4} \psi_{j}+\beta_{5} \theta_{j}\right] \times I_{\left(a_{i}(t-1)=X\right)}+v_{i}+\varepsilon_{i, t}
$$

for $t>1 ; i, j \in\{r, c\} ; j \neq i$.

The results are collected in Table 3 . We estimate four types of models. In model (1), coefficients $\beta_{2}$ to $\beta_{5}$ are constrained to zero. In model (2), coefficients $\beta_{4}$ and $\beta_{5}$ are constrained to zero (i.e., only one's own $\psi$ and $\theta$ matter). In model (3), coefficients $\beta_{2}$ and $\beta_{3}$ are constrained to zero (i.e., only one's opponent's $\psi$ and $\theta$ matter). Finally, model (4) is the unrestricted model. We use the gain and cost parameters in deviation from their sample mean, and estimate all four models on pooled data, then models (1) and (2) on row players only, and models (1) and (3) on column players only. ${ }^{6}$

In Table $3, \beta_{1}$ gives the average sophistication bias. Coefficients $\beta_{2}$ to $\beta_{5}$ indicate how this bias varies with the gains and costs. We hypothesize that players pay more attention to the way their opponent forms their beliefs when the stakes are high. If this is true, then elicited beliefs should be further away from empirical beliefs as one's $\psi$ and $\theta$ increase. We thus expect $\beta_{2}>0$ and $\beta_{3}>0$. Similarly, players should think their opponents react more to their actions when the opponent's $\psi$ and $\theta$ are high. Thus, we expect $\beta_{4}$ and $\beta_{5}$ to be positive as well.

The results indicate that players are responsive to incentives when forming beliefs. While the average impact of having played $X$ in the previous period is always positive and significant, it is modified by the size of the gain and cost parameters. Interestingly, the impact of the gain parameter is more salient than the impact of the cost parameter. Indeed, with the exception of model (3) on pooled data, $\hat{\beta}_{3}$ and $\hat{\beta}_{5}$ remain insignificant in all relevant cases while $\hat{\beta}_{2}$ and $\hat{\beta}_{4}$ are always significantly positive.

\footnotetext{
${ }^{6}$ The full set of models are not estimated on row players and column players only because $\psi_{i}$ and $\theta_{i}$ (resp. $\psi_{j}$ and $\theta_{j}$ ) vary only across row players (resp. column players).
} 


\section{Conclusion}

Usual proxies used in learning models to describe players' belief-formation process postulate that people do not take strategic interactions into account, thus neglecting a concept at the heart of game theory. To investigate its limits, we use experimental games to elicit players' true beliefs and compare them to a common general model of beliefformation. We find that belief proxies are biased as players take strategic interactions into account, particularly when incentives to play strategically are high. Hence, we conclude that the common assumption of purely adaptive players is not innocuous.

\section{References}

Battalio, R., L. Samuelson, and J. Van Huyck (2001): "Optimization Incentives and Coordination Failure in Laboratory Stag Hunt Games," Econometrica, 69(3), 749-64.

CAmerer, C., T.-H. Ho, And J.-K. ChOnG (2002): "Sophisticated ewa learning and strategic teaching in repeated games," Journal of Economic Theory, (104), 137-188.

Cheung, Y.-W., and D. Friedman (1997): "Individual learning in normal form games: Some laboratory results," Games and Economic Behavior, 19(1), 46-76.

Ehrblatt, W. Z., K. Hyndman, E. Y. Ozbay, A. Schotter (2009): "Convergence: An experimental study of teaching and learning in repeated games," mimeo.

NyARKo, Y., And A. SchotTer (2002): “An Experimental Study of Belief Learning using Elicited Beliefs,” Econometrica, 70(3), 971-1006.

TERRACOL, A., AND J. VAKSMANN (2009): "Dumbing down rational players: Learning and teaching in an experimental game," Journal of Economic Behavior and Organization, in press.

ZEILIGER, R. (2000): "A presentation of regate, internet based software for experimental economics.," GATE, http://www.gate.cnrs.fr/ zeiliger/ regate/regateintro.ppt. 
Table 1: Payoff Matrices Used In The Experiments

\begin{tabular}{|c|c|c|c|c|c|}
\hline \multicolumn{3}{|c|}{$H L$} & \multicolumn{3}{|c|}{$H H$} \\
\hline & $X$ & $Y$ & & $X$ & $Y$ \\
\hline Y & 40,45 & 8,37 & $X$ & 40,45 & 0,37 \\
\hline & 39,0 & 12,32 & $Y$ & 37,0 & 12,32 \\
\hline & $L L$ & & & $L H$ & \\
\hline & $X$ & $Y$ & & $X$ & $Y$ \\
\hline & 20,45 & 8,37 & $X$ & 20,45 & 0,37 \\
\hline & 19,0 & 12,32 & $Y$ & 17,0 & 12,32 \\
\hline
\end{tabular}

Figure 1: $\hat{D}_{i}^{X}$

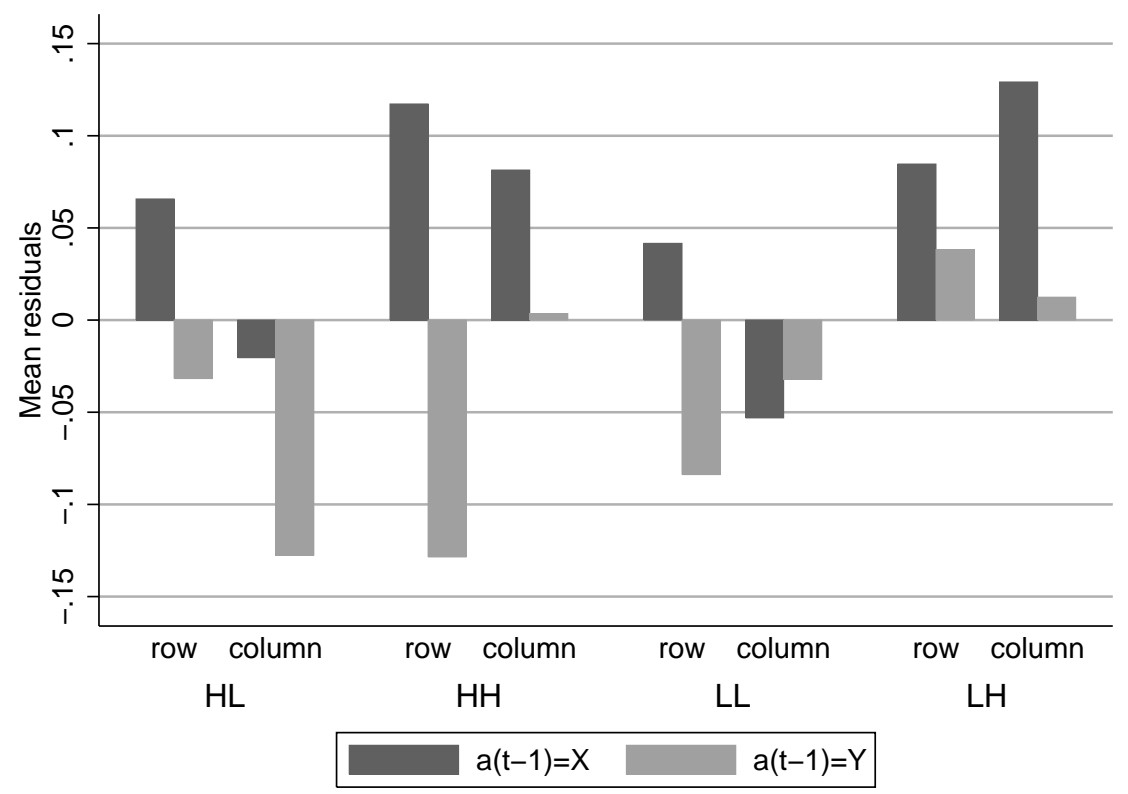

Table 2: Paired t-tests on $\hat{D}_{i}^{X}(t)$, according to the previous action

\begin{tabular}{ccccccccc}
\hline & \multicolumn{2}{c}{$H L$} & \multicolumn{2}{c}{$H H$} & \multicolumn{2}{c}{$L L$} & \multicolumn{2}{c}{$L H$} \\
\cline { 2 - 10 } difference & row & column & row & column & row & column & row & column \\
\cline { 2 - 10 } p-value & 0.097 & 0.107 & 0.245 & 0.077 & 0.125 & -0.021 & 0.046 & 0.116 \\
$\mathrm{~N}$ & 16 & 0.038 & 0.013 & 0.187 & 0.061 & 0.736 & 0.636 & 0.255 \\
\hline
\end{tabular}




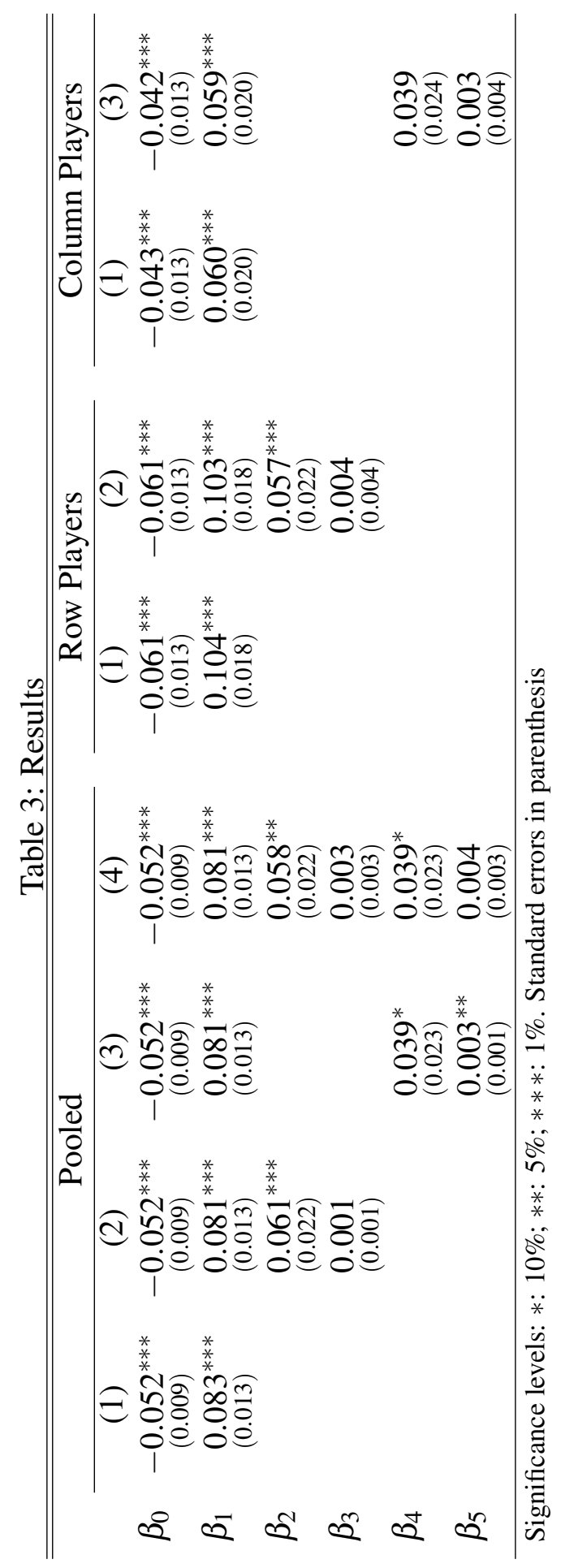




\section{For review purposes only - not meant for publication}

\section{Instructions (translated from French)}

Thank you for participating in this experimental session. During this session, upon the choices you make, you may be able to earn a significant amount of money which will be paid you in private at the end of the experiment. Your identity and those of the other participants will never be disclosed.

This session contains 20 repetitions (which will be labelled "rounds" on your screen). Your final payment corresponds to the sum of the payoffs you earn at each repetition. More precisely, during the 20 rounds of this session, you will make points labelled in Unités Monétaires Expérimentales (UME). At the end of this session, your total payment in UME will be converted into Euros at the rate:

$$
100 \mathrm{UME}=€ 2.1
$$

During this session, you will not be allowed to communicate with other participants. If you have any questions, please raise the hand and the experimenter will publicly answer.

\section{Type and matching}

At the beginning of the session, you will be attached a "type", you can be either of type 1 or of type 2. Your type will remain the same for the whole session. Moreover, you will be matched with a pair partner, picked up at random at the beginning of the session among the participants whose type is different from yours. For example, if you are of type 1 (resp. type 2), your pair partner will be of type 2 (resp. type 1). Your pair partner will be the same for the whole session.

\section{Your decisions}

In each round, every participant can choose among $\mathbf{2}$ decisions: $\mathbf{X}$ or $\mathbf{Y}$. The payoff associated to your decision in a given round depends on your own decision and the 
decision of your pair partner. These payoffs are presented in Tables B.1 or B.2 below if you are respectively of type 1 or of type 2 .

\section{Prediction of other people's decisions}

Prior to choosing a decision in each round, you will be given the opportunity to earn additional money by predicting the decision your pair partner will take in the current round. Thus, at the beginning of each round, you will be asked the following two questions:

- On a scale from 0 to 100 , how likely do you think your pair partner will take decision $\mathrm{X}$ ?

- On a scale from 0 to 100 , how likely do you think your pair partner will take decision $\mathrm{Y}$ ?

For each question you have to key in a number greater than or equal to 0 . The sum of the two numbers you enter has to equal 100. For example, suppose that you think that there is a $65 \%$ chance that your pair partner will take decision $\mathrm{X}$ and a $35 \%$ chance that your pair partner will take decision Y. In this case, you will key in 65 in the upper box on the screen and 35 in the other box. At the end of each round, we will look at the decision actually made by your pair partner and compare his decision to your prediction. We will then pay you for your predictions as follows. Consider the above example: you entered $65 \%$ for decision $\mathrm{X}$ and $35 \%$ for decision Y. Suppose now that your pair partner actually chooses $\mathrm{Y}$. In this case, your payoff for your predictions will be:

$$
4\left[2-(1-0.35)^{2}-(0.65)^{2}\right]
$$

In other words, you will be given a fixed amount of $4 \times 2=8$ points (in UME) from which we will subtract an amount which depends on how inaccurate your predictions were. To do this, when we find out what decision your pair partner has made, we will take the number you assigned to that decision, in this example 35\% (or 0.35) on Y, subtract it from $100 \%$ (or 1), square it and multiply by 4 . Next, we will take the numbers assigned to the decision not made by your pair partner, in this case the $65 \%$ (or 0.65 ) you assigned to $X$, square them and multiply by 4 . These two squared numbers will then be subtracted from the 8 points we initially gave you to determine the final payoff associated to your predictions for the current round.

Note that since your predictions are made before you know what your pair partner has actually chosen, the best thing you can do to maximize the expected size of your prediction payoff is to simply state your true beliefs about what you think your pair partner will do. Any other predictions will decrease the amount you can expect to earn as a prediction payoff. Note also that you can not lose points from making predictions 
but can only earn more points. The worst you can do is predicting that your pair partner will take one particular decision with $100 \%$ certainty but it turns out that he actually takes a different decision. In this case, you will earn 0 point. Similarly, the best you can do is to guess correctly and assign $100 \%$ to that decision which turns out to be the actual decision chosen. Here, you will keep the whole 8 points amount that was given to you at the beginning of the current round.

In each round, you will have two minutes to enter a correct report. If you make a mistake in a report, i.e. if you enter two numbers which sum is different from 100, or if your report is incomplete, you will be able to retry as many times as you want subject to the fact that you have enough time left to do so. If the available time runs out while you have not entered a correct report, the game continues and you will take your decision but you will not get any payoff for your predictions at the current round.

\section{The computer screens}

In each round, you will enter your predictions and take your decisions on different screens represented below.

In the first screen, you will have to report your predictions. You have to enter one number for each decision in the box next to the corresponding question. You will see on your screen the time remaining to report your predictions in figures at the upper right of the screen. Below the two questions, you have a calculator that automatically provides you, in the box "Sum", the sum of the numbers you enter and show you, in the box "Rest", 100 minus the number you have already entered so that it would made computations easier while reporting your predictions. You can change your report at any time provided that you have any time left to do so and when your report sounds to you satisfactory, click $\mathbf{O K}$ to proceed to the next screen to take your decision.

In the next screen, you will have to pick up a decision among the two decisions available. To do so, you have to click on the box corresponding to your choice. You have as time as you want to take your decision.

Once you have reported your predictions and taken your decision, you will get information about the current round. More precisely, you will see recapitulated on a final screen your decision, the decision of your pair partner, your payoff and the payoff of your pair partner associated to your decisions along with the predictions you reported and your prediction payoff. Your predictions, your decisions, the decisions of your partner, and your respective decision payoffs will remain present during the whole session on the bottom of your screen in the table which recapitulates the history of the game by round, so that you will always be able to track what happened in previous round and you will always see which round you are in. Moreover, the last line in the table reminds you of your type so that you could always look at the payoff tables an appropriate way. 


\section{Your Final Payment}

The payoff associated to your predictions will be in addition of what you will make with your decisions. Your final payment in UME will simply be the sum of all payoffs you will make throughout the 20 rounds of this session; it is this total payoff that will be converted into Euros at the above rate.

\section{Tables and Figures From Experimental Instructions}

The two following Tables show subjects' payoffs for game $\mathrm{TP}_{H} / \mathrm{TC}_{L}$, apart from the payoffs contained in these Tables, the instructions are obviously the same in all games.

Table B.1. Description of Payoffs for Type 1 Players

\begin{tabular}{|c|c|c|c|}
\hline Your decision & $\begin{array}{l}\text { Decision of your pair } \\
\text { partner }\end{array}$ & Your payoff & $\begin{array}{l}\text { The payoff of your pair } \\
\text { partner }\end{array}$ \\
\hline $\mathrm{X}$ & $\mathrm{X}$ & 40 & 45 \\
\hline $\mathrm{X}$ & $\mathrm{Y}$ & 8 & 37 \\
\hline $\mathrm{Y}$ & $\mathrm{X}$ & 39 & 0 \\
\hline $\mathrm{Y}$ & $\mathrm{Y}$ & 12 & 32 \\
\hline
\end{tabular}

Table B.2. Description of Payoffs for Type 2 Players

\begin{tabular}{|c|c|c|c|}
\hline Your decision & $\begin{array}{l}\text { Decision of your pair } \\
\text { partner }\end{array}$ & Your payoff & $\begin{array}{l}\text { The payoff of your pair } \\
\text { partner }\end{array}$ \\
\hline $\mathrm{X}$ & $\mathrm{X}$ & 45 & 40 \\
\hline $\mathrm{X}$ & $\mathrm{Y}$ & 0 & 39 \\
\hline $\mathrm{Y}$ & $\mathrm{X}$ & 37 & 8 \\
\hline $\mathrm{Y}$ & $\mathrm{Y}$ & 32 & 12 \\
\hline
\end{tabular}


The screen where you will be asked to report your predictions (the last line of the table shows the appropriate type, type 1 in this example)

Figure 1: Screenshot 1

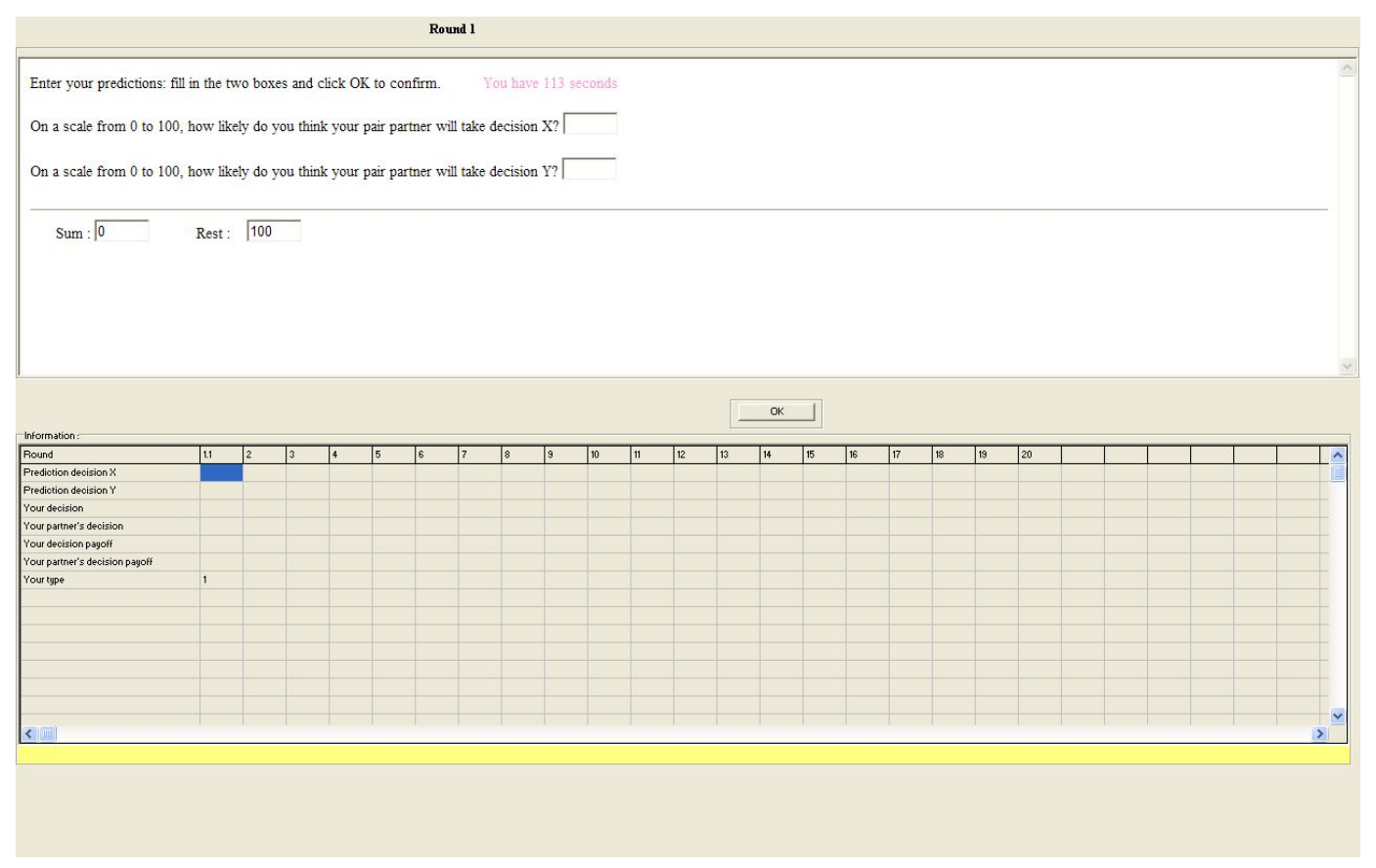


The screen where you will be asked to take your decision (the last line of the table shows the appropriate type, type 1 in this example)

Figure 2: Screenshot 2

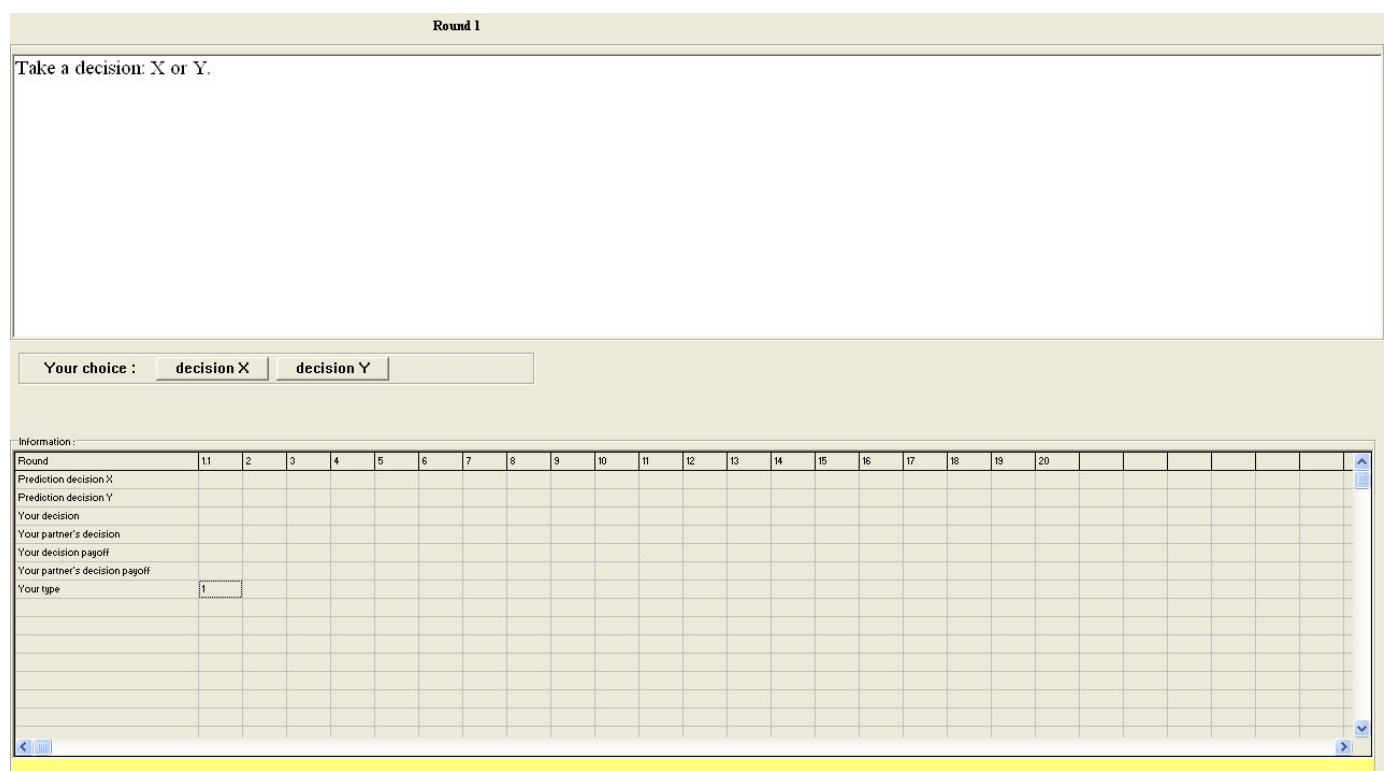


The following screen was not contained in the instructions given to the subjects. It shows an example of how information were recapitulated at the end of each round.

Figure 3: Screenshot 3

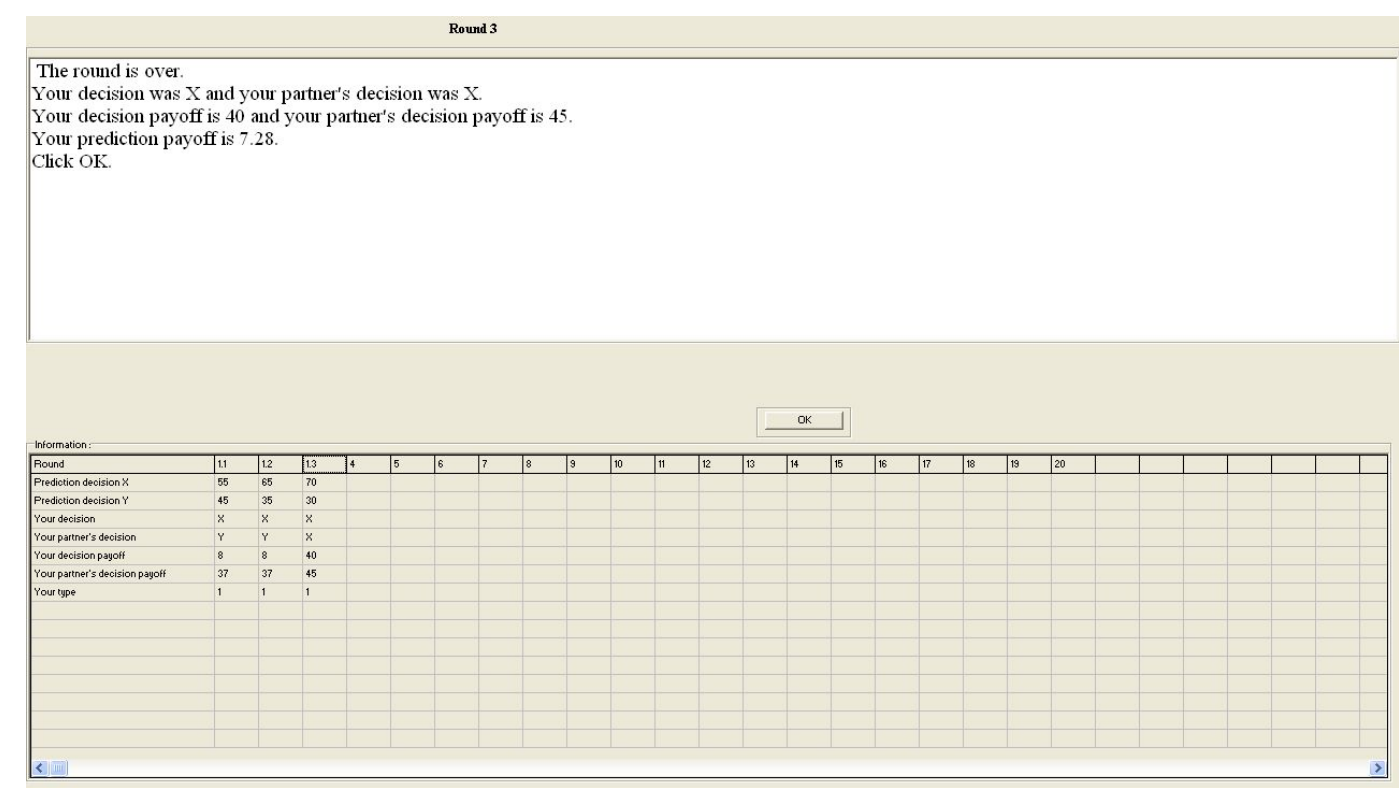

